\title{
Improvement of coordination abilities of qualified athletes specializing in fencing
}

\author{
Georgiy Lopatenko ${ }^{\mathrm{ABCDE}}$, Valeriy Vynogradov ${ }^{\mathrm{ACDE}}$, Lilia Yasko ${ }^{\mathrm{BCD}}$, Ganna Chernenko ${ }^{\mathrm{ABD}}$ \\ Borys Grinchenko Kyiv University, Ukraine
}

Authors' Contribution: A - Study design; B - Data collection; C - Statistical analysis; D - Manuscript Preparation; E - Funds Collection.

\begin{abstract}
Background The aim of the research is to investigate the efficiency of designed complexes of training exercises aimed and Study Aim to improve the coordination abilities of qualified athletes in fencing.

Material and 22 qualified athletes specializing in fencing aged from 15 to 18 took part in the research. The study design Methods included the sequential pedagogical experiment that was realized through the several stages. At the first stage, the preliminary testing of the athletes' coordination abilities $(n=22)$ was conducted. During the preliminary testing the following tests were applied: jumps to the line; shuttle run ( $4 \times 9 \mathrm{~m}$.); T-test, straight touch from en-garde position to the target of $10 \mathrm{~cm}$ in diameter from close range (10 attempts); straight lunge attack from en-garde position to the target of $10 \mathrm{~cm}$ (10 attempts). At the second stage of the pedagogical experiment two complexes of exercises aimed at developing the coordination abilities of the athletes were applied for 3 months. The experimental complexes of exercises were used twice a week. At the third stage, the efficiency of experimental complexes aimed at the developing of coordination abilities of qualified athletes in fencing was checked through a control testing. The Statistica 10 software created by the StatSoft Company was used for statistical processing of data.

Results It was established that during the process of coordination abilities development, the greatest attention should be given to the athletes' ability to control timing, spatial and physical parameters of moves and moves consistency. To improve the process of developing the coordination abilities of the qualified athletes in fencing two complexes of training exercises were developed. The results of the pedagogical experiment confirmed the statistical differences in the levels of the athletes' coordination abilities manifestation before and after using experimental training complexes $(p<0.05)$.

Conclusions: It has been shown that specially developed training complexes could be used during the training process in order to develop and increase the level of coordination abilities of qualified athletes in fencing. The analysis of experts' opinion showed that the development of coordination abilities in fencing should be oriented towards the development of athletes' ability to control timing, spatial and physical parameters of movements.

Keywords: fencing, athletes' preparation, coordination abilities.
\end{abstract}

\section{Introduction}

Modern fencing is characterized by high intensity of training and competitive activities making specific demands on an athlete's organism. The modern sports theory accentuates that athletes' special working capacity and the efficiency of their organisms' functional systems during competitive activities, greatly depends on rationally planned and organized system of physical preparation [1].

The problem of enhancing the efficiency of physical preparation and development of motor skills of athletes in fencing is not new, though it does not lose its relevance being confirmed by a considerable number of recent researches [2-5].

Complex approaches to the organization of fencers' physical preparation are widely represented in the works of Tyshler et al [6] and Ryzhkova [7]. In their works, authors consider physical preparation of athletes in fencing as a multidimensional set of means and methods aimed to develop motor and psychophysiological qualities manifesting during a fencing bout.

\footnotetext{
(c) Georgiy Lopatenko, Valeriy Vynogradov, Lilia Yasko,

Ganna Chernenko, 2021

doi:10.15561/26649837.2021.0402
}

A considerable number of researches were done in order to examine the different aspects of competitive activity in fencing [8-11]. A wide range of authors agreed that one of the most prominent qualities characterizing the elite level athlete and having a direct impact on efficiency of competitive activity is the level of fencer's speed abilities $[2,3,5,12]$. Yet, the latent time of simple and complex hand-eye reaction stands the most prominent component of speed abilities manifestation among the fencers $[5,10,13]$. A. Sorel et al. emphasize that in the course of fencers' physical preparation the main focus should be put on development of the explosive strength, coordination and various components of speed abilities [14].

The results of our previous researches also show the importance of the development of motor skills among the athletes specializing in fencing. It was found that under the influence of the experimental complex of training and extra-training means more prominent changes in the speed of simple and complex visual-motor response were detected [15]. It was also shown that application of experimental training and extra-training means promoted considerable increase of the athletes' speed abilities that 
also positively reflected on the efficiency of competitive activity [11].

A considerably smaller number of scientific researches is devoted to peculiarities of development and improvement of strength, endurance, coordination abilities and flexibility among the athletes specializing in fencing $[3,4,16]$.

di Cagno et al. researched the impact of eccentric workloads on the lower limbs strength indicators of qualified athletes specializing in fencing [3]. The results of the research demonstrated that application of additional workload using specially developed mechanical devices helped to increase the range of attacking moves during advance-lunge, having been reached through the increasing of hip flexors strength [3]. In their researches, J. Redondo et al. describe the impact of 12-week strength training program on the indicators of fencers' maximal and explosive strengths. The authors showed that given experimental program combined with special fencing training means led to the improvement of strength abilities that in its turn also positively affected the manifestation of speed abilities of fencers (single move speed) [4].

The analysis of relevant researches devoted to the peculiarities of physical preparation and development of motor skills among the athletes specializing in fencing demonstrated that researchers and coaches are in constant search of the means and methods that could improve the process of the athletes preparation. Along with that, the conducted analysis showed that in the system of the fencers' preparation there is a lack of scientific-based approaches aimed at developing of coordination abilities of qualified athletes in fencing. It forms the relevance of the research given below.

Hypothesis. Application the specifically developed training exercise sets can increase the level of coordination abilities of qualified athletes in fencing.

The aim of the research is to investigate the efficiency of designed training complexes aimed to improve the coordination abilities of qualified athletes in fencing.

\section{Material and Methods}

\section{Participants.}

22 qualified athletes specializing in fencing aged from 15 to 18 took part in the research. The parents of the participants aged from 15 to 17 and the participants aged 18 gave their consent to take part in the research.

\section{Research Design.}

The research included few stages. At the first stage, we studied the data of recent scientific researches on the peculiarities of physical preparation in fencing, particularly on the approaches of development of motor skills. In order to specify the content and orientation of experimental training complexes aimed to develop coordination abilities of qualified athletes in fencing, the questionnaire of fencing coaches $(n=20)$ was conducted. The further stages of the research included conducting a sequential pedagogical experiment that allowed us to examine the working hypothesis. The choice of a sequential pedagogical experiment is related to the fact that the participants of the research are qualified athletes and it allowed us to achieve more informative samples for analyzing the achieved results. At the second stage, the preliminary testing of the athletes' coordination abilities $(n=22)$ was made. During the preliminary testing the following tests were applied:

1. Jumps to the line (cm) [17].

Task conditions: participant stands on a $90 \mathrm{cmhigh}$ jumping box. On the signal "Go!" the participant jumps to the line drawn on the floor 1 meter away from the jumping box. The participant should land his heels as close as possible to the line. The distance from the participants' heels to the line is measured with the measuring tape. The best result of two trials is recorded.

2. Shuttle run $4 \times 9$ (s) $[17,18]$.

Task conditions: participants sprint back and forth between two parallel lines as fast as possible. Two lines are used as markings, two wooden blocks are put behind one of the lines. Starting position is at the line from the opposite side of the blocks. On the signal "Ready? Go!", the participants run to the other line and pick up a block, then they return to place it behind the starting line. After this, the athletes come back to pick up the second block, then they run with it back across the line. The stopwatch is stopped as the participant passes the line. The quickest of the two trails is recorded.

\section{T-test (s) (Fig.1.) [18].}

Task conditions: a participant starts at the start/finish line. On the signal "Ready? Go!", the participants sprint to cone $\mathrm{A}$ and touch the base of the cone with their right hand. Then they turn left, sprint to cone B, and also touch its base, this time with their left hand. Then they sprint to cone $\mathrm{C}$ and touch the base with their left hand. Then they sprint back to cone A and touch it with the right hand, then to sprint to the start/finish line. The stopwatch is stopped as the participant passes the finish line. The quickest of the two trails is recorded.

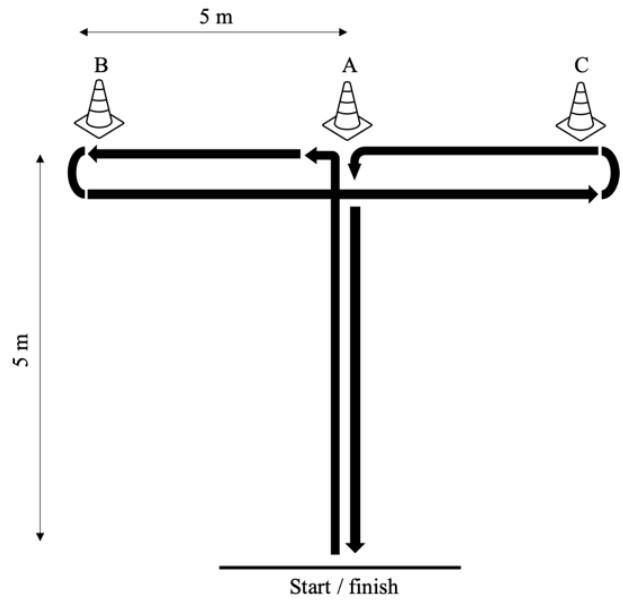

Fig.1. T-test

Besides, the following specialized fencing tests were used:

4. Straight touch from an en-garde position to the $10 \mathrm{~cm}$ target in diameter from close range (10 attempts) [19]. 
Task conditions: a participant stands in the "engarde" position in front of the target with weapon in the leading hand at the close-range distance. A 10-centimeter circle is drawn in the middle of the target. When ready, the participant makes ten touches trying to place the tip of the weapon inside the circle. If the tip of the weapon lands outside of the circle, the touch does not count. The number of successful touches is recorded.

5. Straight lunge attack from an en-garde position to the target of $10 \mathrm{~cm}$ (10 attempts). [19].

Task conditions: the participant stands in the "engarde" position in front of the target with weapon in the leading hand at the middle-range distance. A circle with a diameter of 10 centimeters is drawn in the middle of the target. When ready, the participant makes ten straight lunge attacks trying to place the tip of the weapon inside the circle. If the tip of the weapon lands outside of the circle, the touch does not count. The number of successful touches is recorded.

At the third stage, the experimental training complexes aimed to develop the athletes' coordination abilities are applied to a group of athletes.

The first complex of exercises includes exercises that should be performed with a special coordination ladder (by TRX) $10 \mathrm{~m}$ long, $50 \mathrm{~cm}$ wide, 20 boxes. The given complex includes following exercises:

1. Initial position is behind the ladder. An athlete runs down to the center of the ladder, with each foot coming in contact with boxes, then turns around and runs back to the starting position. Executed once.

2. Initial position is with both feet inside the first box of the ladder. An athlete runs forward with high knees, lifting knees to the waist level, arms are bended at 90 degrees and swinging back and forth to generate momentum. Executed once.

3. Initial position is behind the ladder. An athlete jumps into the first box of the ladder with the right foot, then jumps to the next box with both feet, then jumps to the next box with the left foot, then jumps with both feet again. The sequence continues till the end of the ladder. Executed once.

4. Initial position is behind the ladder. An athlete jumps into the first box of the ladder with both feet, then jumps forward and puts the feet on both sides of the next box, then jumps to the next box with both feet inside the box. The sequence continues till the end of the ladder. Executed once.

5. Initial position is behind the ladder. An athlete jumps into the first box with both feet performing 180-degree turn, then jumps to the next box with both feet performing 180-degree turn in opposite direction. The sequence continues till the end of the ladder. Executed once.

6. Initial position is on the right side of the ladder. An athlete steps sideways with the leading foot into the first box, then cross-steps with the rear foot behind the leading foot into the next box. The sequence continues till the end of the ladder. The exercise should be repeated in the opposite direction.
7. Initial position is on the right side of the ladder. An athlete jumps to the first box landing both feet into the center. Then jumps forward to the second box, spreading legs and landing, so that both feet are outside of the ladder, then jumps to the third box bringing feet back to the same middle position. The sequence continues till the end of the ladder. The exercise should be repeated in the opposite direction.

8. Initial position is on the left side of agility ladder. An athlete takes a lateral step to the right with the right foot into the first box, then immediately follows it with the left foot. Then steps laterally to the left side of the ladder with the left foot and moves the right foot to the next box. Then brings the left foot to meet right, then steps laterally to the right side of the ladder and moves left to the next box. The sequence continues till the end of the ladder. The exercise should be repeated in the opposite direction.

9. Initial position is with feet a little wider than hip-width to the right side of the agility ladder. An athlete steps sideways with the left foot into the first box, follows it right away with the right foot. Then steps sideways with the left foot into the second box, then brings the right foot into that box. The sequence continues till the end of the ladder. The exercise should be repeated in the opposite direction.

10. Initial position is behind the ladder. An athlete steps in with the lead foot, then in with the other foot, out with the lead foot, and out with the other foot. Both feet will touch every square of the entire ladder. The exercise should be repeated by switching the lead foot.

11. Initial position is behind the ladder. An athlete jumps into the first box of the ladder with the right foot and puts hands on the waist, then jumps to the second box with the same foot and puts hands up. The sequence continues till the end of the ladder. The exercise should be repeated with the left foot.

12. An athlete starts from the "en-garde" position with the leading foot in the second box and behind foot in the first box. The athlete advances forward by overstepping lines between the boxes. The exercise should be repeated in opposite direction.

While performing the exercises, the main attention should be paid to the development of correct sequence of movements and relationship among different elements of the given exercise. The understanding of dynamic and kinematic movement parameters should be formed. The athletes' attention was drawn to the rational relocation of body elements, sequence and number of efforts, as well as to tension and relaxation of different muscle groups.

The second complex includes elements of special fencing drills and exercises performed with a partner. This complex is aimed to develop hand motor skills, speed of switching from one action to another, and improving voluntary concentration among the athletes. The given complex includes following exercises:

1. Athlete starts from the "en-garde" position on the side of the fencing piste, holding a tennis ball in the 
leading hand. While advancing, the athlete should throw the ball $50 \mathrm{~cm}$ up and then catch it. The exercise should be repeated in opposite direction.

2. An athlete starts from the "en-garde" position on the side of the fencing piste, holding a tennis ball in the leading hand. While advancing, the athlete should bounce the ball against the floor and then catch it. The exercise should be repeated in opposite direction.

3. Two athletes start from the "en-garde" position facing each other on a distance of 3 meters. Both athletes hold tennis balls in their leading hands. On the signal "Go!", athletes should simultaneously throw the balls to each other and catch the ball thrown by the partner. The exercise should be executed 10 times.

4. Two athletes start from the "en-garde" position facing each other on a distance of 3 meters. One of the athletes holds a tennis ball in the leading hand (athlete A), another athlete has nothing in the hands (athlete B). On the signal "Go!", the athlete A advances forward with one step simultaneously throwing the ball to the athlete B. The athlete B catches the ball simultaneously retreating with one step. Then athlete B throws the ball to the athlete A. The exercise should be executed for one minute.

5. Two athletes start from the "en-garde" position facing each other on a distance of 3 meters. One of the athletes holds a tennis ball in the leading hand (athlete A), another athlete has nothing in the hands (athlete B). On the signal "Go!", the athlete A performs advance lunge attack simultaneously throwing the ball to the athlete B. The athlete B catches the ball simultaneously performing double retreat. Then, the athlete B throws the ball with advance lunge attack to the athlete A. The exercise should be executed for one minute.

6. An athlete starts from the "en-garde" position in the middle of the piste. A partner stands in front of the athlete on a distance of advance lunge attack with a tennis ball in his hand. On the signal "Go!", the partner starts moving constantly changing speed and direction. The athlete should follow the partner keeping the distance of advance lunge attack. While moving, the partner should stop every 10-15 seconds and bounce the ball against the floor in front of him. The athlete should catch the ball with advance lunge attack before it falls to the ground after the bounce. The exercise should be executed for two minutes.

The exercises of the second complex performed with a partner are aimed to develop hand motor skills, speed of switching from one action to another, and improve voluntary concentration among athletes. While performing the exercises, the athletes' attention was drawn to the ability of holding a few objects in sight and switching their attention from one stimulus to the others performing special fencing drills simultaneously. Such actions are related to motive reactions as well as spatial and time anticipations. They form the basis of the athletes' actions in unexpected and unsteady situations.

The designed training complexes were included into the training process of qualified athletes in fencing $(n=22)$ and were applied twice a week for three months in a row. The first complex was used as a part of warm-up routine. The second complex was applied at the beginning of the main part of training session. At the fourth stage, the control testing of the athletes' coordination abilities was done, using the above-described tests. Control testing allowed us to check the efficiency of designed complexes aimed to develop athletes' coordination abilities.

Statistical analysis. To determine statistical significance of the differences between the indicators of the coordination abilities manifestation level among the athletes specializing in fencing before and after using experimental training complexes, the non-parametric criteria for small samples were used (Wilcoxon test), as a sample distribution did not follow the normal distribution law. The significance level was considered $p=0.05$. The Statistica 10 computer software created by the StatSoft Company was used for statistical processing of data.

\section{Results}

To specify the content and peculiarities of coordination abilities development process among the qualified athletes in fencing, the questionnaire of fencing coaches was conducted.

The analysis of questionnaire data showed that $50 \%$ of coaches considered the regulation of dynamic as well as spatial and timing parameters of moves the most important component of coordination abilities among the athletes specializing in fencing. $31 \%$ of respondents noted that intramuscular and intermuscular coordination as the major feature of coordination abilities among fencers, $13 \%$ of respondents noted static and dynamic balance as the dominant manifestation of coordination abilities. Only $6 \%$ of fencing coaches considered spatial orientation as the most important component of coordination abilities.

To develop the coordination abilities among the qualified athletes in fencing, coaches usually use coordinately similar exercises with technical and tactical actions in fencing and exercises (including specialized ones) using additional training equipment. That was noted by $38 \%$ and $28 \%$ of coaches respectively. Apart from that, $22 \%$ of the surveyed coaches considered the varieties of running and jumping exercises as efficient means for developing the athletes' coordination abilities. $10 \%$ of the surveyed used sports games as means of coordination abilities development, $3 \%$ noted that they relied on other training methods.

Taking into account the results of recent researches displayed in special scientific and methodological literature as well as the questionnaire results, two complexes of training exercises aimed to develop coordination abilities among the qualified athletes specializing in fencing were developed.

To check the efficiency of the designed training complexes aimed to develop coordination abilities among the athletes specializing in fencing, we conducted a sequential pedagogical experiment including a preliminary testing of the coordination abilities level 
Table 1. The indicators of manifestation of the athletes' coordination abilities before and after using experimental training complexes

\begin{tabular}{|c|c|c|c|c|}
\hline \multirow{3}{*}{ Test name } & \multicolumn{4}{|c|}{ Testing results } \\
\hline & \multicolumn{2}{|c|}{$\begin{array}{l}\text { Before using experimental } \\
\text { complexes }(n=22)\end{array}$} & \multicolumn{2}{|c|}{$\begin{array}{l}\text { After using experimental complexes } \\
(n=22)\end{array}$} \\
\hline & $\overline{\mathbf{X}}$ & $S$ & $\overline{\mathbf{X}}$ & $S$ \\
\hline Jumps to the line, $\mathrm{cm}$ & 8.91 & 5.81 & $3.32 *$ & 2.98 \\
\hline Shuttle run $(4 \times 9 m), s$ & 11.37 & 1.03 & $10.58^{*}$ & 0.8 \\
\hline T-test, s & 9.57 & 0.54 & $9.41 *$ & 0.45 \\
\hline $\begin{array}{l}\text { Straight touch from "en- } \\
\text { garde" position, number of } \\
\text { touches }\end{array}$ & 9.05 & 0.84 & $9.45^{*}$ & 0.60 \\
\hline $\begin{array}{l}\text { Straight lunge attack from } \\
\text { "en-garde" position, number } \\
\text { of touches }\end{array}$ & 7.55 & 1.5 & $8.64 *$ & 1 \\
\hline
\end{tabular}

Note: * - the differences are statistically significant compared to the data received before using experimental training complexes, of about $\mathrm{p}<0.05$

among the athletes, implementation of experimental complexes into the training process and control testing of coordination abilities.

From the table 1 we can see that after using experimental training complexes, the improvement of indicators of coordination abilities manifestation are observed after all five tests $(\mathrm{p}<0.05)$. The control testing demonstrated that as a result of using of designed training complexes during the training process, the accuracy of completing the jumps to the line test increased by $5.59 \mathrm{~cm}$ $(p<0.05)$. A considerable improvement in the results of the «Jumps to the line» test shows that after the application of experimental training complexes athletes managed to improve the processes of regulation of dynamic and spatial parameters of the movements. To evaluate the complex manifestation of the athletes' coordination abilities, the "Shuttle run" and "T-test"were used. The analysis of the "Shuttle run" results showed that after using the experimental complexes aimed to develop the athletes' coordination abilities the speed of completing the distance improved by $0.79 \mathrm{~s}(\mathrm{p}<0.05)$ on average. The indicators of the "T-test" improved by $0.16 \mathrm{~s}(\mathrm{p}<0.05)$ on average.

The comparative analysis of the results of specialized fencing tests showed that under the influence of experimental complexes, the accuracy of straight touch from the "en guard" position increased by $0.4(p<0.05)$ on average. The accuracy of straight lunge attack to the target of $10 \mathrm{~cm}$ in diameter increased by $1.09(\mathrm{p}<0.05)$ on average.

\section{Discussion}

The development and improvement of coordination abilities take an important place in the system of qualified fencers' physical preparation. The level of coordination abilities plays an important role in the process of motor skills development, mastering technical and tactical actions and their realization in constantly changing conditions of competitive activity. In spite of the fact that the problem of coordination abilities development of athletes is not new [18, 20-22], there is a relevant need of searching various methodological approaches that could be applied in the system of qualified fencers' preparation. There is a lack of recent researches that cover the issue of the development of coordination abilities in fencing. A particular relevance of these issues is also related to the fact that different types of coordination abilities manifestation are sport specific. This fact should be taken into account during the development of specialized training complexes aimed to the improvement of coordination abilities of qualified athletes in fencing $[6,20]$.

The research presented in this article showed that the majority of coaches in fencing believed that among different types of coordination abilities, the most important for fencers were abilities to control timing, spatial and physical parameters of movements as well as a general movement coordination. We believe that this coaches' opinion is related to the specifics of competitive activity in fencing, which requires constant change of movements according to the uncertain conditions of the fencing match.

It is important to notice that the coaches' opinion correspond to the most prominent scientific researches in the field of motor skills development and athletes physical preparation, that shows the importance of coordination abilities in extreme conditions of competitive activity, especially in conditions of space and time deficiency [1, 18].

According to sports experts' opinion and scientific researches, coordination of movements is tightly connected to other types of coordination abilities and, first of all, to the ability of evaluating and regulating dynamic, spatial and timing parameters of movements $[18,20,23]$. The development of experimental complexes 
presupposed that selected training means should positively affect athletes' ability to evaluate and regulate dynamic and spatial parameters of movements. During the development of experimental training complexes, we also took into consideration the opinions of researchers in various kinds of sports noting that training the qualified athletes' coordination abilities would be efficient only if it was realized under conditions of a particular kind of sports $[1,10,22,24]$. It is related to the fact that along with enhancing the athletes' qualification, the generalization and positive shifting in the sphere of abilities and motor skills reduces. General coordination exercises do not have the training effect that has been reached at the previous stages of sports training. Thus, our usage of specialpreparatory exercises adding various complexities during their completion, let us to increase the efficiency of developing coordination abilities of qualified fencers.

It is worth noting that both complexes were based on exercises that require additional training equipment. The training impacts were chosen so that they would provide gradual increase of the demands towards the analyzers' activity related to the accuracy of spatial, timing and dynamic parameters of movements. It was taken into consideration that workload variability is an important element in coordination abilities development, which means that nature, duration and intensity of the exercises should not be the same at every training session [18, 23].

Application of experimental training complexes during the training process allowed us to intensify the functionality of athletes further than traditional means do, and on this basis, increase the level of coordination abilities of qualified fencers.

The conducted research completed the data on contemporary approaches to the organization of physical preparation and development of motor skills of qualified athletes specializing in fencing $[2,3,13,16,25]$. The results of the given research complete the data devoted to the issue of rational organization of qualified athletes' training process in Olympic sports [2, 6, 18, 20].

In our future research, it is expected to investigate the influence of training complexes aimed to develop the coordination abilities of qualified athletes on the efficiency of competitive activity in fencing.

\section{Conclusions}

It has been shown that specially developed training complexes could be used during the training process in order to develop and increase the level of coordination abilities of qualified athletes in fencing. The analysis of experts' opinion showed that the development of coordination abilities in fencing should be oriented towards the development of athletes' ability to control timing, spatial and physical parameters of movements. As a result of the research, it was shown that application of experimental training complexes during the training process of qualified athletes in fencing led to the improvement of the coordination abilities $(p<0.05)$.

\section{Acknowledgements}

The research was completed according to the scientific and research topic «Theoretical and practical principles of using fitness technologies in physical education and sports» (state registration number 0118U001229) of the Faculty of Health, Physical Education and Sports of Borys Grinchenko Kyiv University.

\section{Conflict of interests}

The authors declare no conflict of interests.

\section{References}

1. Platonov VN. System of athletes' preparation in Olympic sports. General theory and its practical implementation. Volume 1. Kiev: Olympic Literature; 2015. (in Russian)

2. Agosti V, Autori M. Fencing Functional Training System (FFTS): A New Pedagogical-Educational Training Project. Sport Science, 2020; Suppl 1(13): 118-122.

3. di Cagno A, Iuliano E, Buonsenso A, Giombini A, Di Martino G, Parisi A, et al. Effects of Accentuated Eccentric Training vs Plyometric Training on Performance of Young Elite Fencers. Journal of Sports Science \& Medicine, 2020; 19(4): 703-713.

4. Redondo JC, Alonso CJ, Sedano S, de Benito AM. Effects of a 12-week strength training program on experimented fencers' movement time. J Strength Cond Res. 2014; 28(12):3375-84. https://doi.org/10.1519/JSC.0000000000000581

5. Turna B. The Effect of Agility Training on Reaction Time in Fencers. Journal of Education and Learning, 2020;9:127-135. https://doi.org/10.5539/jel.v9n1p127

6. Tyshler DA, Movshovich AD. Motor training of fencers. Moscow: Academic project; 2007. (in Russian)

7. Tyshler DA, Ryzhkova LG, Shamis VV. Fencing. Competitive technologies and methodology of specialized training. Moscow: Man; 2013. (in Russian)

8. Milic M, JanićijevićD, NedeljkovicA, Cuk I, Mudric M, García Ramos A. Optimal Instructions to Maximize Attack Efficiency in Beginners and Experienced Fencers. Motor Control, 2020; https://doi.org/10.1123/mc.2020-0065

9. Turner AN, Kilduff LP, Marshall GJG, Phillips J, Noto A, Buttigieg $\mathrm{C}$, et al. Competition Intensity and Fatigue in Elite Fencing. J Strength Cond Res, 2017;31:3128-36. https://doi.org/10.1519/JSC.0000000000001758

10.Nikitenko AO, Busol VA, Nikitenki SA, Shubert VS, Busol VV. Criteria for determining the level of athletes' preparedness among boxers and fencers of different qualification. Naukovo-pedagogichni problemi fizichnoi kul'turi, 2020; 70-75. (in Ukrainian) https://doi.org/10.31392/NPU-nc.series15.2019.1(121)20.13

11.Lopatenko GO. Optimization of training process in pre-start fencing training on the base of out-oftraining means' of mobilization orientation application. Pedagogics, Psychology, Medical-Biological Problems of Physical Training and Sports, 2016; 2:34-39. https://doi.org/10.15561/18189172.2016.0205

12.Chen TL-W, Wong DW-C, Wang Y, Ren S, Yan F, Zhang M. Biomechanics of fencing sport: A scoping review. PLOS ONE, 2017; 12(2): e0171578. https://doi.org/10.1371/journal.pone.0171578

13.Petronijević S, Petrović A, Ćopić N, Jovanović S, Gajić I. The influence of maturation on the speed of the individual hand movements in fencing. Homo Sporticus, 2019; 2: 3136. 
14. Sorel A, Plantard P, Bideau N, Pontonnier C. Studying fencing lunge accuracy and response time in uncertain conditions with an innovative simulator. PLOS ONE, 2019; 14(7), e0218959. https://doi.org/10.1371/journal.pone.0218959

15.Lopatenko GO, Kosik NS, Kosik NL. New approaches to the organization of prestart preparation of qualified athletes in single combats (on an example of fencing). Pedagogics, Psychology, Medical-Biological Problems of Physical Training and Sports, 2015;4:33-37. https://doi.org/10.15561/18189172.2015.0406

16. Turner A, James N, Dimitriou L, Greenhalgh A, Moody J, Fulcher D, Mias E, et al. Determinants of Olympic fencing performance and implications for strength and conditioning training. Journal of Strength and Conditioning Research. 2014. 28(10):3001-3011. https://doi.org/10.1519/JSC.0000000000000478

17.Liakh VI. Coordination abilities: diagnostics and development. Moscow: TVT Divizion; 2006. (in Russian)

18.Platonov VN. Motor skills and physical preparation of athletes. Kiev: Olympic Literature; 2017. (in Russian)

19.Fencing. Curriculum for youth sports schools, specialized youth sports schools, schools of high sportsmanship, schools of the Olympic reserve. Kyiv: VPC "Expres"; 2006. (in Ukrainian)
20.Boloban V. Technologies for managing the process of teaching of dificult sports coordination exercises. Teoriia i metodika fizichnogo vikhovannia isportu, 2020;2:23-35. (in Ukrainian) https://doi.org/10.32652/tmfvs.2020.2.23-35

21.Charykova IA. The diagnostic program neurophysiological and psychophysiological control for an integrated approach to improve the coordination abilities. Minsk: Republican Scientific and Practical Center of Sports; 2016. (in Russian)

22.Enoiu R-S, Badau D, Teris S. Developing Coordination As A Determinant Factor Of Proprioception In Football. Sport and Society, 2019:84-90. https://doi.org/10.36836/UAIC/FEFS/10.39

23.Krutsevych TU. Theory and methodology of physical education. Volume 1. Kiev: Olympic Literature; 2003. (in Russian)

24.Gu YD, Popik S, Dobrovolskiy S. Hand punch movement kinematics of boxers with different qualification levels. International Journal of Biomedical Engineering and Technology. 2018;28(4):366-376.

25.Kriventsova I, Iermakov S, Bartík P, Nosko M, Wojciech J C. Optimization of student-fencers' tactical training. Ido Movement for Culture. Journal of Martial Arts Anthropology, 2017; 17(3): 21-30.

\section{Information about the authors:}

Georgiy Lopatenko; (Corresponding Author); http://orcid.org/0000-0001-9223-248X; h.lopatenko@kubg.edu.ua; Borys Grinchenko Kyiv University; Kyiv, Ukraine.

Valeriy Vynogradov; https://orcid.org/0000-0002-1168-5557; v.vynohradov@kubg.edu.ua; Borys Grinchenko Kyiv University; Kyiv, Ukraine.

Lilia Yasko; http://orcid.org/0000-0002-6649-1899 ; I.yasko@kubg.edu.ua; Borys Grinchenko Kyiv University; Kyiv, Ukraine.

Ganna Cherhenko; https://orcid.org/0000-0003-2560-732X; h.chernenko@kubg.edu.ua; Borys Grinchenko Kyiv University; Kyiv, Ukraine.

Cite this article as:

Lopatenko G, Vynogradov V, Yasko L, Chernenko G. Improvement of coordination abilities of qualified athletes specializing in fencing. Pedagogy of Physical Culture and Sports, 2021;25(4):208-214. https://doi.org/10.15561/26649837.2021.0402

This is an Open Access article distributed under the terms of the Creative Commons Attribution License, which permits unrestricted use, distribution, and reproduction in any medium, provided the original work is properly cited (http://creativecommons.org/licenses/by/4.0/deed.en).

Received: 10.02 .2021

Accepted: 10.03.2021; Published: 30.08.2021 